\title{
Home Mechanical Ventilation for COPD: High-Intensity Versus Target Volume Noninvasive Ventilation
}

\author{
Jan H Storre MD, Elena Matrosovich MD, Emelie Ekkernkamp MD, David J Walker MD, \\ Claudia Schmoor PhD, Michael Dreher MD, and Wolfram Windisch MD
}

\begin{abstract}
BACKGROUND: High-intensity noninvasive ventilation (HI-NIV) is the most effective means of improving several physiological and clinical parameters in subjects with chronic hypercapnic COPD. Whether the newer hybrid mode using target tidal volume noninvasive ventilation (target $\mathbf{V}_{T} \mathrm{NIV}$ ) provides additional benefits remains unclear. METHODS: Subjects with COPD successfully established on long-term HI-NIV were switched to target $V_{T}$ NIV. Optimal target $V_{T}$ settings according to nocturnal transcutaneous $\mathbf{P}_{\mathrm{CO}_{2}}$ measurements were achieved following a randomized crossover trial using $8 \mathrm{~mL} / \mathrm{kg}$ ideal body weight and $110 \%$ of individual $V_{T}$ during HI-NIV, respectively. The following parameters were compared at the beginning of the trial while subjects were on HI-NIV, and after 3 months on optimal target $V_{T}$ NIV: sleep quality by polysomnography, overnight gas exchange, subjects' tolerance, overnight pneumotachygraphic measurements during NIV, healthrelated quality of life (severe respiratory insufficiency questionnaire), exercise capacity (6-min walk test), and lung function. RESULTS: Ten of 14 subjects completed the study. There were no differences between HI-NIV and target $V_{T}$ NIV in any of the above-mentioned parameters. Specifically, the mean overnight transcutaneous $\mathbf{P}_{\mathrm{CO}}$, was equivalent under each form of ventilation (both $45 \pm 5 \mathrm{~mm} \mathrm{Hg}, P=.75$ ). CONCLUSIONS: Switching subjects from well-established HI-NIV to target $V_{T}$ NIV shows no clinical benefits in chronic hypercapnic COPD. In particular, sleep quality, the control of nocturnal hypoventilation, daytime hypercapnia, overnight ventilation patterns, subjects' tolerance, health-related quality of life, lung function, and exercise capability were all similar in subjects who underwent HI-NIV and target $V_{T}$ NIV. Nevertheless, target $V_{T}$ NIV might offer some physiological advantages in breathing pattern and might be beneficial in some individual patients. (German Clinical Trials Register [www.drks.de] Registration DRKS00000450.) Key words: Chronic obstructive pulmonary disease; mechanical ventilation; sleep quality; target volume; ventilation mode. [Respir Care 2014;59(9):1389-1397. (C) 2014 Daedalus Enterprises]
\end{abstract}

\section{Introduction}

High-intensity noninvasive positive-pressure ventilation (HI-NIV), a controlled form of ventilation that is com- bined with high inspiratory pressures, was introduced as a new therapeutic option for patients with COPD with stable

\footnotetext{
Drs Storre and Windisch are affiliated with the Department of Pneumology, Cologne-Merheim Hospital, Kliniken der Stadt Köln, Witten/Herdecke University Hospital, Cologne; Drs Storre, Matrosovich, Ekkernkamp, Walker, Dreher, and Windisch are affiliated with the Department of Pneumology, University Hospital Freiburg, Freiburg; Dr Matrosovich is affiliated with the Department of Internal Medicine, Klinikum Nuremberg Nord, Nuremberg; Dr Schmoor is affiliated with the Clinical Trials Unit, University Medical Center, Freiburg; and Dr Dreher is affiliated with the Department of Cardiology, Pneumology, and Vascular Medicine, University Hospital, Aachen, Germany.
}

Dr Storre presented this work in abstract form at the European Respiratory Society Annual Congress, held September 1-5, 2012, in Vienna, Austria.

The study group received open research grants from Breas Medical, Respironics, ResMed Germany, Weinmann, and Vivisol. Study devices and consumables were provided by Breas Medical. Dr Storre received speaking fees from the following companies: Breas Medical, Respironics, ResMed Germany, Heinen und Löwenstein, Werner und Müller Medizintechnik, SenTec AG, Radiometer Medical Aps and Keller Medical; honoraria from Respironics and Boehringer Ingelheim Pharma for expertise; and travel funding for national and international research con- 
chronic hypercapnia, based on its capacity to improve physiological and clinical parameters, including control of nocturnal hypoventilation, daytime hypercapnia, exerciserelated dyspnea, lung function, and health-related quality of life. ${ }^{1,2}$ In addition, this approach has been shown to be superior to the conventional approach of low-intensity NIV, which combines purely assisted forms of ventilation with considerably lower inspiratory pressures, and fails to consistently improve gas exchange and the other important aforementioned parameters. ${ }^{2,3}$ However, the concern has been raised that constant high inspiratory pressures are not well tolerated by all patients, and that HI-NIV might even have the capacity to impair cardiac function. ${ }^{4}$ Therefore, alternative modes of NIV need to be evaluated for their potential to provide additional benefits to these patients.

Target volume NIV (target $\mathrm{V}_{\mathrm{T}}$ NIV) was introduced as a hybrid mode of ventilation aimed at combining the advantages of volume- and pressure-preset NIV. ${ }^{5}$ Nearly all studies on target $\mathrm{V}_{\mathrm{T}}$ NIV were performed on subjects suffering from obesity hypoventilation syndrome (OHS)..$^{5-9}$ To this end, evidence suggests that target $\mathrm{V}_{\mathrm{T}}$ NIV does not provide clear benefits to subjects with OHS if pressurepreset NIV is optimized in relation to gas exchange. ${ }^{9}$ However, there is only sparse and inconclusive information available on the effect of target $\mathrm{V}_{\mathrm{T}}$ NIV in subjects with COPD ${ }^{8}$ Furthermore, HI-NIV therapy in patients with COPD is clearly different than the pressure-preset mode to which target $\mathrm{V}_{\mathrm{T}}$ NIV has been compared in patients with OHS. Therefore, the findings on target $\mathrm{V}_{\mathrm{T}}$ NIV in OHS cannot be directly transferred to patients with COPD.

Based on these considerations, the current study was performed to systematically evaluate the effects of target $\mathrm{V}_{\mathrm{T}}$ NIV versus HI-NIV as forms of home mechanical ventilation. In particular, it was investigated whether target $\mathrm{V}_{\mathrm{T}}$ NIV was capable of promoting further improvements in sleep quality, ventilation patterns, health-related quality of life, lung function, and exercise capability in subjects already established on HI-NIV. Thereby, care was taken to determine the best settings for target $\mathrm{V}_{\mathrm{T}} \mathrm{NIV}$ that

gresses from Breas Medical, Heinen und Löwenstein, Respironics, SenTec, Vivisol, Weinmann, and Werner und Müller Medizintechnik. Dr Ekkernkamp received travel funding for national and international research congresses from Vivisol Germany and ResMed Germany. Dr Walker received speaking fees from Heinen und Löwenstein, and travel funding for national and international research congresses from Vivisol Germany, Sapio Life, and Bayer. Dr Dreher received speaking fees from VitalAire, ResMed, Dräger Medical, and Respironics; travel funding from ResMed and Vivisol; funding for research and funding for a member of staff from ResMed; and consulting fees from Linde. Dr Windisch was reimbursed by Maquet for attending conferences on intensive care medicine; received speaking fees from Dräger Medical, Heinen und Löwenstein, Respironics, Weinmann, ResMed, Covidien, Linde, Maquet, and Siare; and the following funds for research: grants from Respironics

\section{QUICK LOOK}

\section{Current knowledge}

High-intensity noninvasive ventilation (HI-NIV) has been proposed to reverse dyspnea, improve quality of life, and reverse hypoventilation in subjects with chronic hypercapnic COPD. HI-NIV is typically delivered using a pressure controlled mode. The use of target volume NIV in hypercapnic COPD has not been described.

\section{What this paper contributes to our knowledge}

There was no difference in sleep quality, control of nocturnal hypoventilation, daytime hypercapnia, overnight ventilation patterns, subjects' tolerance, healthrelated quality of life, lung function, and exercise capability in subjects who underwent HI-NIV in the pure pressure or target volume modes.

would have the potential to provide additional benefits to those gained from HI-NIV.

\section{Methods}

The study protocol was approved by the Institutional Review Board for Human Studies at Albert-Ludwigs University (Freiburg, Germany), and was performed in accordance with ethical standards laid down in the Declaration of Helsinki. Written informed consent was obtained from all subjects. The study was performed as a single-center study at the Department of Pneumology, University Medical Centre (Freiburg, Germany).

\section{Subjects}

Subjects with COPD and chronic hypercapnic respiratory failure who were already established on HI-NIV for at least 3 months before the study were eligible for inclusion. ${ }^{1,2}$ Subjects were recruited during a routine follow-up hospital visit. ${ }^{10}$ Only patients who reported good compli-

grants from Breas Medical, and a research grant from Weinmann and Vivisol in 2013; and received honoraria from Maquet, for having attended advisory board meetings. The other authors have disclosed no conflicts of interest.

Correspondence: Jan Hendrik Storre MD, Department of Pneumology, Cologne-Merheim Hospital Kliniken der Stadt Köln gGmbH, Witten/Herdecke University Hospital, Ostmerheimer Strasse 200, D-51109 Cologne, Germany. E-mail: storrej@kliniken-koeln.de.

DOI: $10.4187 /$ respcare.02941 


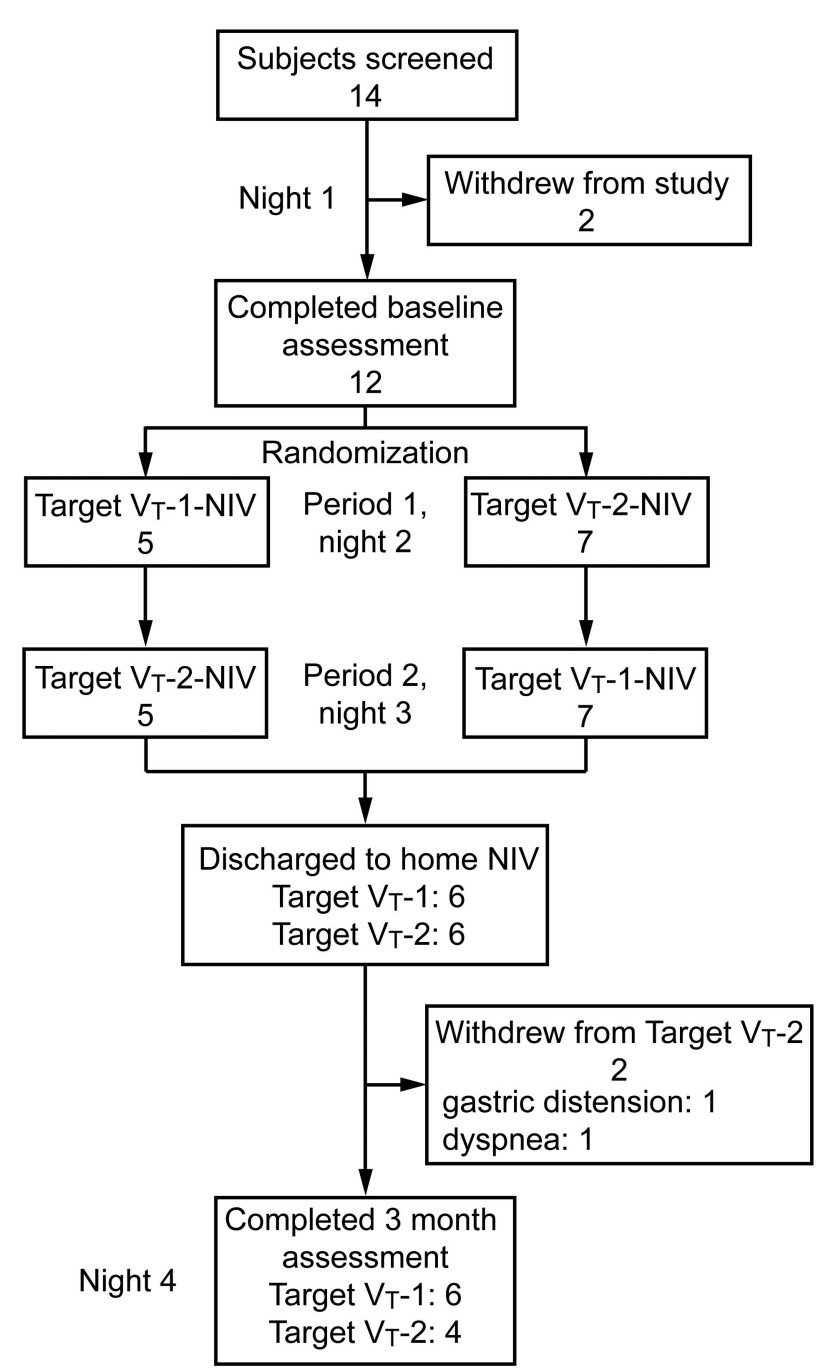

Fig. 1. Trial flow chart. HI-NIV = high-intensity noninvasive ventilation; Target $\mathrm{V}_{\mathrm{T}} \mathrm{NIV}=$ target volume noninvasive ventilation.

ance to HI-NIV with overnight use of at least $6 \mathrm{~h}$ were included. Subjects were excluded if they presented with evidence of acute respiratory failure $(\mathrm{pH}<7.35)$ or signs of respiratory infection (eg, fever or purulent sputum). In addition, only target $\mathrm{V}_{\mathrm{T}}$ NIV-naive subjects were included.

\section{Study Design}

The trial profile is illustrated in Figure 1. After baseline assessment with HI-NIV, which also included nocturnal measurements during the first night, the first part of the study had a randomized, open-label, 2-treatment, 2-periodcrossover design aimed at establishing optimal target $\mathrm{V}_{\mathrm{T}}$ NIV. Subjects were randomized to receive either the target $\mathrm{V}_{\mathrm{T}^{-1}} \mathrm{NIV} /$ target $\mathrm{V}_{\mathrm{T}^{-}}$NIV sequence or target $\mathrm{V}_{\mathrm{T}^{-2}}$ $\mathrm{NIV} /$ target $\mathrm{V}_{\mathrm{T}^{-}}$N NIV sequence during the following 2 consecutive nights. After the first night with target $\mathrm{V}_{\mathrm{T}}$
NIV, subjects were switched to the alternative mode of target $\mathrm{V}_{\mathrm{T}}$ NIV. Accordingly, all measurements were performed during 3 consecutive nights.

Subjects were ventilated with a Vivo 40 or Vivo 50 ventilator (Breas Medical, Mölnlycke, Sweden) to establish target $\mathrm{V}_{\mathrm{T}}$ NIV. The 2 different target $\mathrm{V}_{\mathrm{T}}$ NIV settings were chosen according to previous recommendations: $8 \mathrm{~mL} / \mathrm{kg}$ ideal body weight (target $\left.\mathrm{V}_{\mathrm{T}^{-}}\right)^{6}$ and $110 \%$ of individual $\mathrm{V}_{\mathrm{T}}$ during HI-NIV (target $\mathrm{V}_{\mathrm{T}}-2$ ). ${ }^{8}$ For target $\mathrm{V}_{\mathrm{T}} \mathrm{NIV}$, minimal inspiratory airway pressure (IPAP) was set to $5 \mathrm{~cm} \mathrm{H}_{2} \mathrm{O}$ lower than IPAP used during HI$\mathrm{NIV}$, and maximal IPAP was set to $35 \mathrm{~cm} \mathrm{H}_{2} \mathrm{O}$. If an IPAP $\geq 35 \mathrm{~cm} \mathrm{H}_{2} \mathrm{O}$ was used during HI-NIV, this pressure was adapted to target $\mathrm{V}_{\mathrm{T}}$ NIV as the maximal IPAP. Further ventilator settings and oxygen flows were carried over from the last-used settings of HI-NIV and not changed during any measurements.

Subjects were discharged for home mechanical ventilation with target $\mathrm{V}_{\mathrm{T}}$ NIV settings, which produced lower mean nocturnal transcutaneous $\mathrm{P}_{\mathrm{CO}_{2}}\left(\mathrm{P}_{\mathrm{tcCO}_{2}}\right)$. Final assessments were performed following readmission after 3 months of target $\mathrm{V}_{\mathrm{T}} \mathrm{NIV}$.

\section{Measurements}

Lung function parameters (Masterlab-Compact Labor, Jaeger, Hochberg, Germany) were investigated at baseline and after 3 months, in accordance with international guidelines (Fig. 1). ${ }^{11,12}$ In addition, mouth occlusion pressures (ZAN100, ZAN Gerätetechnik, Oberthulba, Germany), ${ }^{13}$ exercise capacity during the 6-min walk test, ${ }^{2}$ subjective sleep quality according to the Epworth sleepiness scale, ${ }^{14}$ and health-related quality of life as determined by the severe respiratory insufficiency (SRI) questionnaire ${ }^{15}$ were documented. Subjects' compliance for target $\mathrm{V}_{T}$ NIV was analyzed by calculating the hours of use per day during home mechanical NIV from operating hours of the device being used. In addition, subjects reported subjective tolerance of HI-NIV after night 1 and target $\mathrm{V}_{\mathrm{T}}$ NIV after night 4 by an individual questionnaire with 5 items (scale $1-5$, indicating multiple complaints to no complaints): ventilation quality, overly high air flow, sleep quality, gastric distention, and sufficient air flow. Arterial blood gas samples (AVL Omni, Roche Diagnostics, Graz, Austria) were taken from the arterialized earlobe. $\mathrm{P}_{\mathrm{tcCO}_{2}}$ was monitored using a digital monitor (SenTec DM, software 06.21.1, version 04.04.05; SenTec, Therwil, Switzerland) during each night, as previously described. ${ }^{16}$ Full polysomnography (Somnoscreen plus; Somnomedics, Melbourne, Florida) was recorded at baseline during HI-NIV and after 3 months of target $\mathrm{V}_{\mathrm{T}}$ NIV (Fig. 1), as previously described in detail. ${ }^{3}$ In addition, pulse oximetry (Somnoscreen plus) was recorded during target $\mathrm{V}_{\mathrm{T}}$ NIV titration on the first visit. For measurements of ventilation patterns, a pneu- 
Table 1. Pneumotachygraphic Measurements of Ventilation Pattern, Nocturnal Gas Exchange, and Pulse Oximetry During Nocturnal NIV Target $\mathrm{V}_{\mathrm{T}^{-1}}$ NIV vs Target $\mathrm{V}_{\mathrm{T}^{-}}$- NIV

\begin{tabular}{|c|c|c|c|c|c|}
\hline Subject Measurements $(n=12)$ & Period & $\begin{array}{c}\text { Target } \mathrm{V}_{\mathrm{T}^{-1}} \\
\text { NIV }\end{array}$ & $\begin{array}{c}\text { Target } \mathrm{V}_{\mathrm{T}^{-}}-2 \\
\text { NIV }\end{array}$ & $\begin{array}{l}\text { Treatment Effect } \\
\quad(95 \% \mathrm{CI})\end{array}$ & $P$ \\
\hline \multicolumn{6}{|c|}{ Nocturnal gas exchange and pulse oximetry } \\
\hline \multirow[t]{2}{*}{ Mean $\mathrm{P}_{\mathrm{tcCO}_{2}}(\mathrm{~mm} \mathrm{Hg})$} & 1 & $45.0 \pm 3.5$ & $48.8 \pm 5.9$ & $0.1(-1.0$ to 1.2$)$ & .80 \\
\hline & 2 & $50.0 \pm 5.4$ & $45.9 \pm 3.2$ & & \\
\hline \multirow[t]{2}{*}{ Maximal $\mathrm{P}_{\mathrm{tcCO}_{2}}(\mathrm{~mm} \mathrm{Hg})$} & 1 & $48.8 \pm 4.6$ & $52.8 \pm 6.9$ & $0.8(-0.6$ to 2.2$)$ & .25 \\
\hline & 2 & $54.7 \pm 6.0$ & $49.2 \pm 3.8$ & & \\
\hline \multirow[t]{2}{*}{$\mathrm{pH}$ at $5 \mathrm{AM}$} & 1 & $7.38 \pm 0.06$ & $7.40 \pm 0.03$ & $-0.01(-0.02$ to 0.00$)$ & .10 \\
\hline & 2 & $7.39 \pm 0.03$ & $7.39 \pm 0.06$ & & \\
\hline \multirow{2}{*}{$\mathrm{P}_{\mathrm{aCO}_{2}}$ at $5 \mathrm{AM}(\mathrm{mm} \mathrm{Hg})$} & 1 & $46.0 \pm 3.9$ & $50.5 \pm 7.4$ & $1.4(-0.6$ to 3.3$)$ & .15 \\
\hline & 2 & $52.7 \pm 7.2$ & $45.5 \pm 3.0$ & & \\
\hline \multirow{2}{*}{$\mathrm{P}_{\mathrm{aO}_{2}}$ at $5 \mathrm{AM}(\mathrm{mm} \mathrm{Hg})$} & 1 & $72.9 \pm 10.3$ & $71.7 \pm 13.1$ & $-1.3(-12.6$ to 10.0$)$ & .80 \\
\hline & 2 & $73.7 \pm 16.9$ & $77.4 \pm 19.0$ & & \\
\hline \multirow{2}{*}{$\mathrm{HCO}_{3}{ }^{-}$at $5 \mathrm{AM}(\mathrm{mmol} / \mathrm{L})$} & 1 & $26.5 \pm 3.9$ & $29.8 \pm 2.0$ & $0.3(-0.2$ to 0.7$)$ & .29 \\
\hline & 2 & $30.3 \pm 2.4$ & $26.5 \pm 3.8$ & & \\
\hline \multirow{2}{*}{ Mean $\mathrm{S}_{\mathrm{PO}_{2}}(\%)$} & 1 & $94.2 \pm 1.5$ & $91.6 \pm 3.6$ & $0.3(-0.5$ to 1.1$)$ & .39 \\
\hline & 2 & $92.3 \pm 2.9$ & $94.5 \pm 1.9$ & & \\
\hline \multirow{2}{*}{ Minimum $\mathrm{S}_{\mathrm{PO}_{2}}(\%)$} & 1 & $83.0 \pm 5.1$ & $81.3 \pm 7.8$ & $1.2(-4.5$ to 6.8$)$ & .64 \\
\hline & 2 & $86.7 \pm 5.6$ & $86.0 \pm 2.9$ & & \\
\hline \multirow[t]{2}{*}{ Mean heart rate (beats/min) } & 1 & $67.2 \pm 17.1$ & $76.4 \pm 11.7$ & $-0.7(-5.9$ to 4.4$)$ & .75 \\
\hline & 2 & $74.7 \pm 10.5$ & $65.3 \pm 15.8$ & & \\
\hline \multirow[t]{2}{*}{ Maximal heart rate (beats/min) } & 1 & $144.2 \pm 46.2$ & $141.9 \pm 50.5$ & $-2.5(-39.8$ to 34.9$)$ & .88 \\
\hline & 2 & $128.7 \pm 33.9$ & $135.8 \pm 23.9$ & & \\
\hline \multicolumn{6}{|c|}{ Nocturnal pneumotachygraphic measurements } \\
\hline \multirow[t]{2}{*}{ Mean inspiratory volume (mL) } & 1 & $914 \pm 200$ & $852 \pm 219$ & $33(-114$ to 181$)$ & .62 \\
\hline & 2 & $954 \pm 341$ & $949 \pm 240$ & & \\
\hline \multirow{2}{*}{ Mean expiratory volume (mL) } & 1 & $368 \pm 157$ & $413 \pm 118$ & $-44(-83$ to 15$)$ & .15 \\
\hline & 2 & $366 \pm 171$ & $389 \pm 163$ & & \\
\hline \multirow[t]{2}{*}{ Mean leak volume (mL) } & 1 & $546 \pm 320$ & $439 \pm 222$ & $-4.2(-227$ to 218$)$ & .97 \\
\hline & 2 & $445 \pm 393$ & $561 \pm 341$ & & \\
\hline \multirow[t]{2}{*}{ Mean airway pressure $\left(\mathrm{cm} \mathrm{H}_{2} \mathrm{O}\right)$} & 1 & $9.8 \pm 1.4$ & $10.8 \pm 2.4$ & $-0.1(-1.6$ to 1.4$)$ & .89 \\
\hline & 2 & $10.8 \pm 1.1$ & $10.1 \pm 0.5$ & & \\
\hline \multirow[t]{2}{*}{ Peak inspiratory pressure $\left(\mathrm{cm} \mathrm{H}_{2} \mathrm{O}\right)$} & 1 & $17.9 \pm 2.2$ & $19.8 \pm 3.0$ & $-0.5(-2.5$ to 1.5$)$ & .59 \\
\hline & 2 & $19.0 \pm 1.5$ & $18.0 \pm 1.2$ & & \\
\hline \multirow[t]{2}{*}{$\operatorname{PEEP}\left(\mathrm{cm} \mathrm{H}_{2} \mathrm{O}\right)$} & 1 & $6.0 \pm 1.5$ & $6.9 \pm 2.3$ & $0.00(-1.5$ to 1.5$)$ & .96 \\
\hline & 2 & $7.1 \pm 1.5$ & $6.1 \pm 0.8$ & & \\
\hline \multirow[t]{2}{*}{ f measured (breaths/min) } & 1 & $20.4 \pm 1.6$ & $22.5 \pm 2.6$ & $-0.2(-1.5$ to 1.2$)$ & .80 \\
\hline & 2 & $22.0 \pm 1.3$ & $20.2 \pm 1.1$ & & \\
\hline \multicolumn{6}{|c|}{$\begin{array}{l}\text { Data are presented as mean } \pm \mathrm{SD} \text { unless otherwise noted. } \\
\text { Target } \mathrm{V}_{\mathrm{T}} \mathrm{NIV}=\text { target tidal volume noninvasive ventilation } \\
\mathrm{P}_{\mathrm{tcCO}}=\text { transcutaneous carbon dioxide pressure } \\
\mathrm{f}=\text { breathing frequency }\end{array}$} \\
\hline
\end{tabular}

motachograph (RSS 100 research pneumotach system, Korr Medical Technologies, Salt Lake City, Utah) was placed between the mask and the exhalation port as previously described. ${ }^{6,10,17}$

\section{Statistics}

This study originally aimed to compare the relative outcomes after 6 weeks of target $\mathrm{V}_{\mathrm{T}^{-}}-1 \mathrm{NIV}$ and 6 weeks of target $\mathrm{V}_{\mathrm{T}}-2 \mathrm{NIV}$, respectively, in a randomized crossover design. Sample size calculation of 14 subjects was based on sleep efficiency, which served as the primary end point. The study was calculated to have $90 \%$ power to show a difference between both target $\mathrm{V}_{\mathrm{T}}$ settings by a 2-sided level $\alpha$ of .05; this was predicted under the assumption that a $10 \%$ difference in sleep efficiency existed between both settings with an SD of 10\%.7,18 However, this study design with two 6-week periods of home mechanical ventilation turned out to be intolerable for the subjects. Of the first 4 subjects screened, 3 refused to participate in the study due 
Table 2. Ventilator Settings and Pneumotachygraphic Measurements of Ventilation Patterns During Nocturnal NIV HI-NIV vs Target $\mathrm{V}_{\mathrm{T}}$ NIV

\begin{tabular}{|c|c|c|c|c|}
\hline Subject Measurements $(n=10)$ & HI-NIV & $\begin{array}{l}\text { Target } V_{T} \\
\text { NIV }\end{array}$ & $\begin{array}{l}\text { Treatment Effect } \\
\quad(95 \% \mathrm{CI})\end{array}$ & $P$ \\
\hline \multicolumn{5}{|l|}{ Ventilator settings } \\
\hline Mean oxygen flow rate $(\mathrm{L} / \mathrm{min})$ & $1.9 \pm 1.1$ & $1.9 \pm 1.1$ & & \\
\hline IPAP $\left(\mathrm{cm} \mathrm{H}_{2} \mathrm{O}\right)$ & $25.7 \pm 6.2$ & & & \\
\hline Minimal IPAP $\left(\mathrm{cm} \mathrm{H}_{2} \mathrm{O}\right)$ & & $20.7 \pm 6.2$ & & \\
\hline Maximal IPAP $\left(\mathrm{cm} \mathrm{H}_{2} \mathrm{O}\right)$ & & $35.3 \pm 0.9$ & & \\
\hline Target $\mathrm{V}_{\mathrm{T}^{-1}}(\mathrm{~mL}, n=6)$ & & $535 \pm 41$ & & \\
\hline Target $\mathrm{V}_{\mathrm{T}}-2(\mathrm{~mL}, n=4)$ & & $655 \pm 121$ & & \\
\hline EPAP $\left(\mathrm{cm} \mathrm{H}_{2} \mathrm{O}\right)$ & $5.1 \pm 1.7$ & $5.1 \pm 1.7$ & & \\
\hline f preset (breaths/min) & $18.6 \pm 1.2$ & $18.6 \pm 1.2$ & & \\
\hline Inspiratory time (s) & $1.1 \pm 0.1$ & $1.1 \pm 0.1$ & & \\
\hline \multicolumn{5}{|c|}{ Nocturnal pneumotachygraphic measurements } \\
\hline Mean inspiratory volume $(\mathrm{mL})$ & $1089 \pm 371$ & $1032 \pm 366$ & $-57(-307$ to 192$)$ & .62 \\
\hline Mean expiratory volume $(\mathrm{mL})$ & $388 \pm 195$ & $498 \pm 510$ & $109(-243$ to 461$)$ & .50 \\
\hline Mean leak volume (mL) & $701 \pm 486$ & $629 \pm 420$ & $-106(-311$ to 100$)$ & .27 \\
\hline Mean airway pressure $\left(\mathrm{cm} \mathrm{H}_{2} \mathrm{O}\right)$ & $10.9 \pm 1.7$ & $10.3 \pm 1.6$ & $-0.6(-2.0$ to 0.8$)$ & .35 \\
\hline Peak inspiratory pressure $\left(\mathrm{cm} \mathrm{H}_{2} \mathrm{O}\right)$ & $20.5 \pm 3.8$ & $17.9 \pm 2.6$ & $-2.6(-5.3$ to 0.2$)$ & .06 \\
\hline $\operatorname{PEEP}\left(\mathrm{cm} \mathrm{H}_{2} \mathrm{O}\right)$ & $6.4 \pm 2.0$ & $6.7 \pm 1.4$ & $0.3(-1.0$ to 1.6$)$ & .62 \\
\hline f measured (breaths/min) & $21.2 \pm 2.3$ & $20.9 \pm 1.7$ & $-0.3(-1.7$ to 1.1$)$ & .66 \\
\hline \multicolumn{5}{|c|}{$\begin{array}{l}\text { Data are presented as mean } \pm \text { SD unless otherwise noted. } \\
\text { HI-NIV = high-intensity noninvasive ventilation } \\
\text { Target } V_{\mathrm{T}} \mathrm{NIV}=\text { target tidal volume noninvasive ventilation } \\
\mathrm{IPAP}=\text { inspiratory positive airway pressure } \\
\text { EPAP = expiratory positive airway pressure } \\
\mathrm{f}=\text { breathing frequency }\end{array}$} \\
\hline
\end{tabular}

to the 2 planned consecutive visits within the following 3 months.

Consequently, the study design was changed as outlined above, now comparing the 2 different target $\mathrm{V}_{\mathrm{T}}$ NIV settings 1 and 2 only with regard to the end point nocturnal gas exchange, pulse oximetry, and pneumotachygraphic measurements. A comparison of both target $\mathrm{V}_{\mathrm{T}}$ NIV settings with regard to the end point sleep efficiency could not be performed in a within-subject comparison. A between-subjects comparison of the target $\mathrm{V}_{\mathrm{T}}$ NIV settings 1 and 2 after discharge with regard to sleep efficiency was not performed, because the study, planned for a withinsubject comparison, was underpowered for this situation. Afterward, sleep efficiency was compared between the optimal target $\mathrm{V}_{\mathrm{T}}$ NIV selected at discharge and HI-NIV at baseline. For the comparison of both target $\mathrm{V}_{\mathrm{T}} \mathrm{NIV}$ settings 1 and 2 in the crossover part of the study, an analysis of variance model was used that included treatment, period, and randomized sequence as fixed effects, and subject within sequence as a random effect. For the comparison of the selected target $\mathrm{V}_{\mathrm{T}}$ NIV setting with HI-NIV at baseline, paired $t$ tests were used. The treatment effects were estimated with $95 \%$ confidence intervals and tested with a 2 -sided level $\alpha$ of .05. Comparisons with regard to the individual questionnaire were performed with paired Wilcoxon tests.
Sample size calculations were performed with nQuery Advisor 7.0 (Statistical Solutions, Boston, Massachusetts). All statistical analyses were performed with the SAS 9.2 statistical analysis system (SAS Institute, Cary, North Carolina).

\section{Results}

Fourteen subjects were included in the study (Fig. 1). In 2 subjects, baseline polysomnography was associated with technical problems, and reassessments were refused by the participants. Therefore, 12 subjects ( 7 female, $63.3 \pm 8.2 \mathrm{y}$, body mass index $27.6 \pm 6.3 \mathrm{~kg} / \mathrm{m}^{2}$ ) were randomized to receive target $\mathrm{V}_{\mathrm{T}^{-}}$NIV/target $\mathrm{V}_{\mathrm{T}^{-}}$N NIV sequence or target $\mathrm{V}_{\mathrm{T}^{-}}$- NIV/target $\mathrm{V}_{\mathrm{T}^{-1}}$ NIV sequence (Fig. 1).

Overnight comparisons of target $\mathrm{V}_{\mathrm{T}^{-1}} \mathrm{NIV}$ and target $\mathrm{V}_{\mathrm{T}}-2$ NIV are provided in Table 1 . Six subjects representing lower overnight $\mathrm{P}_{\text {tcCO}}$ with target $\mathrm{V}_{\mathrm{T}^{-1}}$ NIV and 6 subjects representing lower overnight $\mathrm{P}_{\text {tcCO}}$ with target $\mathrm{V}_{\mathrm{T}}-2$ NIV were identified and discharged with the favored target $\mathrm{V}_{\mathrm{T}}$ NIV setting for home NIV, respectively. The difference in mean overnight $\mathrm{P}_{\mathrm{tcCO}_{2}}$ during the favorable and nonfavorable target $\mathrm{V}_{\mathrm{T}}$ setting ranged between 0.3 and $4.1 \mathrm{~mm} \mathrm{Hg}$ (mean $1.9 \pm 1.5 \mathrm{~mm} \mathrm{Hg}$ ). Subsequently, 2 subjects dropped out while on target $\mathrm{V}_{\mathrm{T}^{-}}-2$ NIV due to gastric distention and dyspnea, respectively (Fig. 1). 
Table 3. Polysomnographic Measurements and Nocturnal Gas Exchange During Nocturnal NIV HI-NIV vs Target $\mathrm{V}_{\mathrm{T}}$ NIV

\begin{tabular}{|c|c|c|c|c|}
\hline Subject Measurements $(n=10)$ & HI-NIV & $\begin{array}{c}\text { Target } V_{T} \\
\text { NIV }\end{array}$ & $\begin{array}{l}\text { Treatment Effect } \\
\quad(95 \% \mathrm{CI})\end{array}$ & $P$ \\
\hline \multicolumn{5}{|l|}{ Polysomnography } \\
\hline Sleep efficiency $(\%)$ & $64.2 \pm 20.9$ & $61.0 \pm 19.6$ & $-3.3(-11.1$ to 4.6$)$ & .37 \\
\hline TST (min) & $240 \pm 100$ & $251 \pm 88$ & $11(-26$ to 48$)$ & .53 \\
\hline NREM stage 1 (\% TST) & $26.8 \pm 17.8$ & $30.9 \pm 16.3$ & $4.1(-7.3$ to 15.5$)$ & .44 \\
\hline NREM stage 2 (\% TST) & $48.4 \pm 19.0$ & $49.9 \pm 13.7$ & $1.5(-14.9$ to 17.9$)$ & .84 \\
\hline NREM stage $3+4(\%$ TST $)$ & $10.8 \pm 10.8$ & $9.0 \pm 8.2$ & $-1.8(-5.4$ to 1.8$)$ & .28 \\
\hline REM sleep (\% TST) & $14.0 \pm 8.2$ & $10.2 \pm 5.7$ & $-3.8(-12.0$ to 4.5$)$ & .33 \\
\hline Arousals (No./h) & $17.7 \pm 15.7$ & $20.3 \pm 15.9$ & $2.6(-11.8$ to 16.9$)$ & .70 \\
\hline AHI score (events/h) & $3.1 \pm 3.7$ & $2.1 \pm 3.0$ & $-1.0(-4.3$ to 2.4$)$ & .53 \\
\hline Mean heart rate (beats/min) & $70.2 \pm 20.8$ & $68.3 \pm 11.7$ & $-1.9(-12.2$ to 8.4$)$ & .69 \\
\hline Maximal heart rate (beats/min) & $113.9 \pm 46.8$ & $96.3 \pm 22.8$ & $-17.6(-50.7$ to 15.5$)$ & .26 \\
\hline ODI (events/h) & $2.9 \pm 3.4$ & $2.2 \pm 3.1$ & $-0.7(-4.0$ to 2.5$)$ & .63 \\
\hline Mean $\mathrm{S}_{\mathrm{pO}_{2}}(\%)$ & $92.8 \pm 3.5$ & $92.4 \pm 2.4$ & $-0.4(-2.0$ to 1.2$)$ & .59 \\
\hline Minimum $\mathrm{S}_{\mathrm{pO}_{2}}(\%)$ & $85.6 \pm 7.3$ & $84.2 \pm 4.2$ & $-1.4(-6.8$ to 4.0$)$ & .57 \\
\hline \multicolumn{5}{|l|}{ Nocturnal gas exchange } \\
\hline Mean $\mathrm{P}_{\mathrm{tcCO}_{2}}(\mathrm{~mm} \mathrm{Hg})$ & $44.8 \pm 5.0$ & $45.3 \pm 4.6$ & $0.5(-3.1$ to 4.1$)$ & .75 \\
\hline Maximal $\mathrm{P}_{\mathrm{tcCO}_{2}}(\mathrm{~mm} \mathrm{Hg})$ & $50.3 \pm 7.9$ & $49.3 \pm 4.2$ & $-1.0(-5.2$ to 3.3$)$ & .62 \\
\hline $\mathrm{pH}$ at $5 \mathrm{AM}$ & $7.40 \pm 0.04$ & $7.41 \pm 0.04$ & $0.00(-0.01$ to 0.02$)$ & .66 \\
\hline $\mathrm{P}_{\mathrm{aCO}_{2}}$ at $5 \mathrm{AM}(\mathrm{mm} \mathrm{Hg})$ & $47.1 \pm 8.4$ & $47.2 \pm 3.9$ & $0.1(-4.8$ to 4.9$)$ & .98 \\
\hline $\mathrm{P}_{\mathrm{aO}_{2}}$ at $5 \mathrm{AM}(\mathrm{mm} \mathrm{Hg})$ & $79.1 \pm 12.5$ & $77.6 \pm 18.2$ & $-1.5(-10.1$ to 7.2$)$ & .71 \\
\hline $\mathrm{HCO}_{3}{ }^{-}$at $5 \mathrm{AM}(\mathrm{mmol} / \mathrm{L})$ & $28.3 \pm 3.6$ & $29.0 \pm 1.8$ & $0.7(-1.1$ to 2.5$)$ & .40 \\
\hline $\begin{array}{l}\text { Data are presented as mean } \pm \mathrm{SD} \text { unless otherw } \\
\mathrm{HI}-\mathrm{NIV}=\text { high-intensity noninvasive ventilation } \\
\text { Target } \mathrm{V}_{\mathrm{T}} \mathrm{NIV}=\text { target tidal volume noninvasiv } \\
\mathrm{TST}=\text { total sleep time } \\
\text { NREM = nonrapid eye movement sleep } \\
\mathrm{REM}=\text { rapid eye movement sleep } \\
\mathrm{No} \text { = number } \\
\mathrm{AHI}=\text { apnea-hypopnea index } \\
\mathrm{ODI}=\text { oxygen desaturation index } \\
\mathrm{P}_{\mathrm{tcCO}_{2}}=\text { transcutaneous carbon dioxide pressure }\end{array}$ & & & & \\
\hline
\end{tabular}

Thereafter, 10 subjects ( 5 female, $64.5 \pm 8.5 \mathrm{y}$, body mass index $29.1 \pm 5.8 \mathrm{~kg} / \mathrm{m}^{2}$ ) completed the trial. These subjects had used HI-NIV for $51.6 \pm 51.1$ months before screening. Subjects were ventilated with Breas Vivo 40 $(n=6)$, and Breas Vivo $50(n=4)$ during the study. Four subjects used nasal masks, and 6 subjects used oronasal masks. Ventilator settings and patterns comparing HI-NIV and target $\mathrm{V}_{\mathrm{T}}$ NIV are given in Table 2. Accordingly, polysomnographic measurements and data on nocturnal gas exchange are shown in Table 3 and Figures 2 and 3, and daytime assessments are displayed in Table 4. With regard to the primary end point, sleep efficiency, the mean $\left( \pm \mathrm{SD}\right.$ ) difference between optimal target $\mathrm{V}_{\mathrm{T}} \mathrm{NIV}$ setting and HI-NIV at baseline was $-3.3 \pm 11.0 \%$ (95\% CI -11.1 to $4.6, P=.37$ ) (see Fig. 2). On an individual basis, mean overnight $\mathrm{P}_{\text {tcCO}}$ values were lower during HI-NIV in 4 subjects (difference to target $\mathrm{V}_{\mathrm{T}} \mathrm{NIV}$ ranging from 2.1 to $8.1 \mathrm{~mm} \mathrm{Hg}$ ), but were lower during target $\mathrm{V}_{\mathrm{T}}$ NIV in 6 subjects (difference to HI-NIV ranging from 0.3 to $6.4 \mathrm{~mm} \mathrm{Hg}$ ) (see Fig. 3). Subjects used target
$\mathrm{V}_{\mathrm{T}}$ NIV for $8.1 \pm 1.1$ (minimum 6.0 , maximum 9.5 ) $\mathrm{h} / \mathrm{d}$ during home mechanical ventilation.

Subanalysis of the effects between the elected target $\mathrm{V}_{\mathrm{T}^{-}}-1 \mathrm{NIV}(n=6)$ versus target $\mathrm{V}_{\mathrm{T}^{-}}-2 \mathrm{NIV}(n=4)$ after 3 months of home mechanical ventilation revealed no differences in each of the parameters investigated (data not presented).

\section{Discussion}

This is the first trial to investigate the effects of individually set target $\mathrm{V}_{\mathrm{T}}$ NIV with successfully established HI-NIV in subjects with COPD with stable hypercapnic respiratory failure. Even though the 2 different settings for target $\mathrm{V}_{\mathrm{T}}$ NIV generally produced comparable results, there were clear differences between the 2 settings on an individual basis regarding nocturnal $\mathrm{P}_{\text {tcCO}}$ measurements.

There are 2 major findings arising from this study: the transfer of COPD subjects to optimal target $\mathrm{V}_{\mathrm{T}}$ NIV did not improve sleep efficiency and overall sleep quality, and 


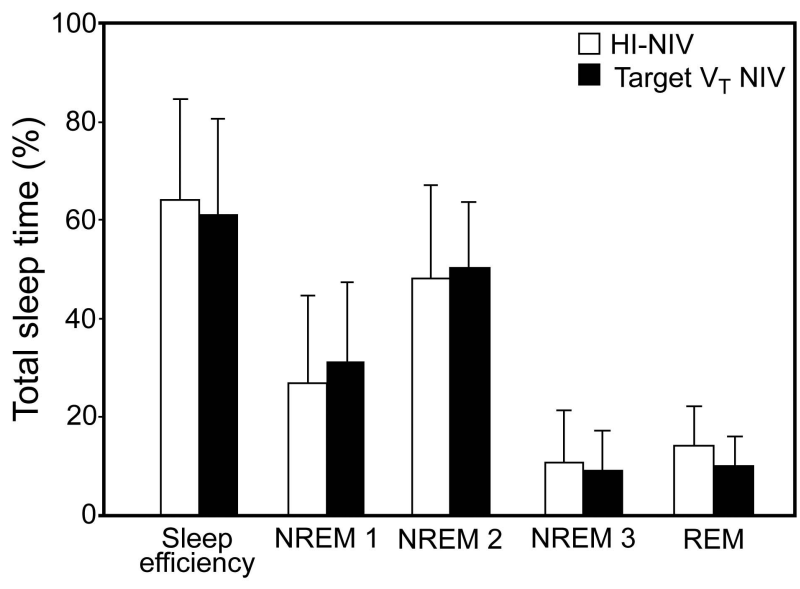

Fig. 2. Sleep efficiency and sleep stages following high-intensity noninvasive ventilation (HI-NIV) and target tidal volume noninvasive ventilation (Target $\mathrm{V}_{\mathrm{T}} \mathrm{NIV}$ ). NREM = nonrapid eye movement sleep; REM = rapid eye movement sleep.

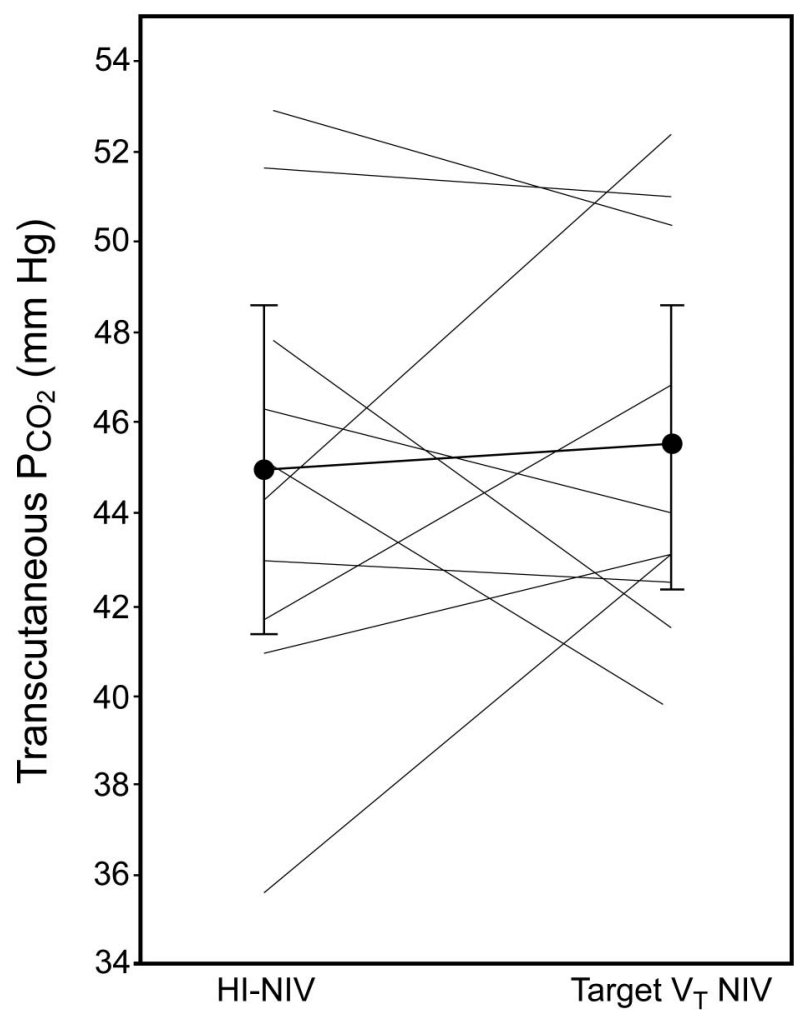

Fig. 3. Individual changes in nocturnal gas exchange determined by mean overnight transcutaneous $\mathrm{P}_{\mathrm{CO}_{2}}$ following high-intensity noninvasive ventilation ( $\mathrm{HI}-\mathrm{NIV}$ ) and target tidal volume noninvasive ventilation (Target $\mathrm{V}_{\mathrm{T}} \mathrm{NIV}$ ). In addition, mean \pm SD are given for all subjects $(n=10)$.

it produced similarly effective results as HI-NIV therapy in terms of outcome parameters such as the control of nocturnal hypoventilation, daytime hypercapnia, overnight ventilation patterns, subjects' tolerance, health-related quality of life, lung function, and exercise capability. The single result favoring target $\mathrm{V}_{\mathrm{T}}$ NIV was the psychological well-being subscale of the SRI questionnaire; however, this needs to be interpreted with caution.

Another interesting observation was that there was a tendency toward a more physiologically advantageous ventilation pattern, with lower leakage and higher expiratory volumes reflecting the tidal volume and showing a clear trend in lower inspiratory pressures applying target $\mathrm{V}_{\mathrm{T}}$ NIV compared with HI-NIV. ${ }^{6}$ Thereby, the strength of the study lies in the fact that these ventilation pattern parameters were assessed by external independent pneumotachygraphic measurements. The observation of physiologically advantageous ventilation was also reported in subjects with OHS on target $\mathrm{V}_{\mathrm{T}}$ NIV, ${ }^{6}$ suggesting that this might be an overall benefit of the therapy. ${ }^{6}$ An explanation might be the principle of target $\mathrm{V}_{\mathrm{T}}$ NIV, because expiratory volumes are calculated by the device during ventilation and the IPAP is adjusted accordingly to guarantee the predefined target $\mathrm{V}_{\mathrm{T}}$. Therefore, target $\mathrm{V}_{\mathrm{T}} \mathrm{NIV}$ is suggested to respond to variation of lung resistance and compliance of the patient during mechanical ventilation. However, larger trials are required to substantiate these findings, and the clinical benefit of these physiological circumstances remains unclear.

Of note, sleep quality did not deteriorate when subjects were switched from HI-NIV to target $\mathrm{V}_{\mathrm{T}} \mathrm{NIV}$, even though target $\mathrm{V}_{\mathrm{T}}$ NIV parameters were aggressively set to achieve a maximal reduction in $\mathrm{P}_{\mathrm{tcCO}_{2}}$. This is in contrast to another study on subjects with OHS, where aggressive target $\mathrm{V}_{\mathrm{T}}$ NIV settings reportedly produced deterioration in sleep quality compared with conventional pressure-preset NIV. ${ }^{7}$ In addition, overall compliance and tolerance of target $\mathrm{V}_{\mathrm{T}}$ NIV was comparable to HI-NIV. Two subjects dropped out on home mechanical target $\mathrm{V}_{\mathrm{T}}-2$ NIV. However, analyzing data of daily use and subjects' tolerance by the individual questionnaires did not support intolerance to target $\mathrm{V}_{\mathrm{T}}$ NIV.

Overall, this indicates that findings on target $\mathrm{V}_{\mathrm{T}}$ NIV cannot be generalized to other patients with long-term NIV. Nevertheless, these findings potentially show that aggressive forms of target $\mathrm{V}_{\mathrm{T}}$ NIV are not harmful to subjects with COPD. This is an interesting aspect for practical implications of NIV modes for patients with COPD. Although not investigated in the present trial, target $\mathrm{V}_{\mathrm{T}} \mathrm{NIV}$ might serve as an alternative in patients unable to tolerate the high ventilator settings (especially a fixed high IPAP) applied during the establishment of HI-NIV, particularly in view of the fact that target $\mathrm{V}_{\mathrm{T}}$ NIV is individually capable of improving alveolar ventilation in subjects already receiving HI-NIV as shown in this trial. However, to confirm this approach, further investigations with this topic are needed. An additional interesting observation is given 


\section{HOME NIV FOR COPD}

Table 4. Lung Function, Mouth Occlusion Pressures, 6-Min Walk Test, Epworth Sleepiness Scale, Health-Related Quality of Life Assessment by the SRI Questionnaire, and Individual Questionnaire after NIV HI-NIV vs Target $\mathrm{V}_{\mathrm{T}}$ NIV

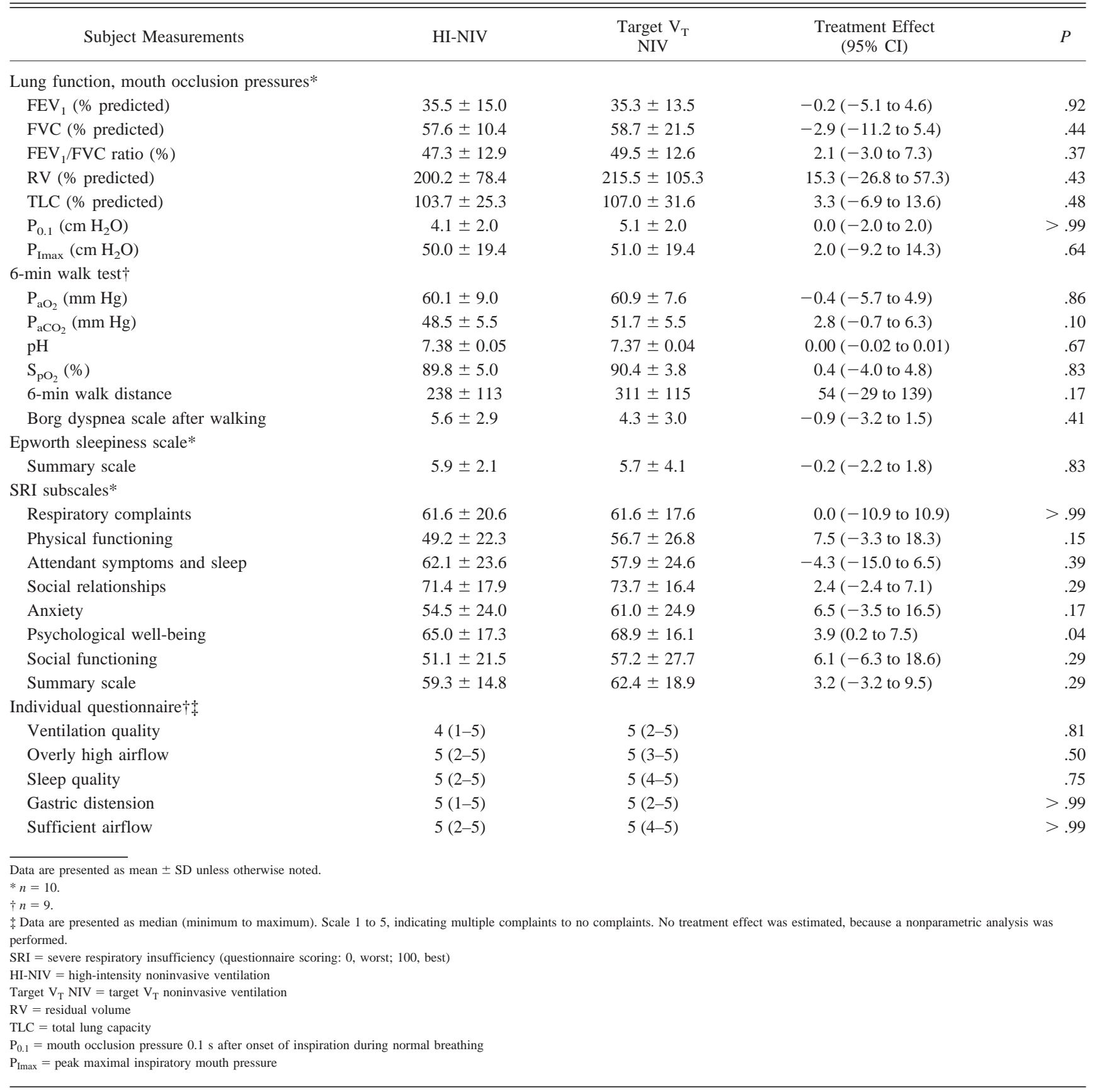

by the distance of the subjects in the 6-min walk test. Here, a trend for a longer distance after establishment of target $\mathrm{V}_{\mathrm{T}}$ NIV was detectable. However, this difference did not reach statistical significance, but this finding is in line with the previous assumption that target $\mathrm{V}_{\mathrm{T}}$ NIV is at least not harmful for the patients.

Some limitations of the current study need to be addressed. First, the initial plan to compare two 6-week periods of target $\mathrm{V}_{\mathrm{T}}$ NIV was not feasible. Therefore, one might speculate that the time needed by subjects to become acclimatized to the different target $\mathrm{V}_{\mathrm{T}}$ NIV-settings was too short during the initiation visit. On the other hand, we extended the treatment period of target $\mathrm{V}_{\mathrm{T}}$ NIV to 3 months at home, which was favorable according to the selected study end points and in comparison to wellestablished HI-NIV. Second, the drop-out rate was relatively high (4 of 14 subjects), which led to a considerably low sample size. This difficulty is in line with a previous 


\section{HOME NIV FOR COPD}

study, which described the challenge of recruiting subjects with severe COPD into clinical trials with demanding study protocols. ${ }^{19}$ Nevertheless, it remains questionable whether larger subject groups would have led to more statistically significant differences, given the similarity in outcomes between HI-NIV and target $\mathrm{V}_{\mathrm{T}}$ NIV.

\section{Conclusions}

In conclusion, target $\mathrm{V}_{\mathrm{T}}$ NIV does not offer additional clinical benefits in comparison to well-established HI-NIV in chronic hypercapnic subjects with COPD. In particular, sleep quality, the control of nocturnal hypoventilation, daytime hypercapnia, overnight ventilation patterns, subjects' tolerance, health-related quality of life, lung function, and exercise capability were all comparable and similar in subjects who underwent HI-NIV and target $\mathrm{V}_{\mathrm{T}}$ NIV. Therefore, switching from well-established HI-NIV to target $\mathrm{V}_{\mathrm{T}}$ NIV is generally not recommended. Nevertheless, target $\mathrm{V}_{\mathrm{T}}$ NIV might offer some physiological advantages in breathing pattern and might be beneficial in some individual patients.

\section{ACKNOWLEDGMENTS}

We acknowledge all participants for the effort they devoted to this study. We acknowledge Sandra Dieni PhD (Department of Molecular Psychiatry, University Hospital Freiburg, Freiburg, Germany) for helpful comments on the manuscript before submission.

\section{REFERENCES}

1. Windisch W, Haenel M, Storre JH, Dreher M. High-intensity noninvasive positive pressure ventilation for stable hypercapnic COPD. Int J Med Sci 2009;6(2):72-76.

2. Dreher M, Storre JH, Schmoor C, Windisch W. High-intensity versus low-intensity non-invasive ventilation in patients with stable hypercapnic COPD: a randomised crossover trial. Thorax 2010;65(4): 303-308.

3. Dreher M, Ekkernkamp E, Walterspacher S, Walker D, Schmoor C, Storre JH, Windisch W. Noninvasive ventilation in COPD: impact of inspiratory pressure levels on sleep quality. Chest 2011;140(4): 939-945.

4. Lukácsovits J, Carlucci A, Hill N, Ceriana P, Pisani L, Schreiber A, et al. Physiological changes during low- and high-intensity noninvasive ventilation. Eur Respir J 2012;39(4):869-875.
5. Windisch W, Storre JH. Target volume settings for home mechanical ventilation: great progress or just a gadget? Thorax 2012;67(8): 663-665.

6. Storre JH, Seuthe B, Fiechter R, Milioglou S, Dreher M, Sorichter S, Windisch W. Average volume-assured pressure support in obesity hypoventilation: A randomized crossover trial. Chest 2006;130(3): 815-821.

7. Janssens JP, Metzger M, Sforza E. Impact of volume targeting on efficacy of bi-level non-invasive ventilation and sleep in obesityhypoventilation. Respir Med 2009;103(2):165-172.

8. Ambrogio C, Lowman X, Kuo M, Malo J, Prasad AR, Parthasarathy S. Sleep and non-invasive ventilation in patients with chronic respiratory insufficiency. Intensive Care Med 2009;35(2):306-313.

9. Murphy PB, Davidson C, Hind MD, Simonds A, Williams AJ, Hopkinson NS, Moxham J, Polkey M, Hart N. Volume targeted versus pressure support non-invasive ventilation in patients with super obesity and chronic respiratory failure: a randomised controlled trial. Thorax 2012;67(8):727-734.

10. Storre JH, Bohm P, Dreher M, Windisch W. Clinical impact of leak compensation during non-invasive ventilation. Respir Med 2009; 103(10):1477-1483.

11. Miller MR, Crapo R, Hankinson J, Brusasco V, Burgos F, Casaburi $\mathrm{R}$, et al. General considerations for lung function testing. Eur Respir J 2005;26(1):153-161.

12. Miller MR, Hankinson J, Brusasco V, Burgos F, Casaburi R, Coates A, et al. Standardisation of spirometry. Eur Respir J 2005;26(2): 319-338.

13. Windisch W, Hennings E, Sorichter S, Hamm H, Criée CP. Peak or plateau maximal inspiratory mouth pressure: which is best? Eur Respir J 2004;23(5):708-713.

14. Johns MW. A new method for measuring daytime sleepiness: the Epworth sleepiness scale. Sleep 1991;14(6):540-545.

15. Windisch W, Freidel K, Schucher B, Baumann H, Wiebel M, Matthys $\mathrm{H}$, Petermann F. The severe respiratory insufficiency (SRI) questionnaire: a specific measure of health-related quality of life in patients receiving home mechanical ventilation. J Clin Epidemiol 2003; 56(8):752-759

16. Storre JH, Magnet FS, Dreher M, Windisch W. Transcutaneous monitoring as a replacement for arterial $\mathrm{PCO}(2)$ monitoring during nocturnal non-invasive ventilation. Respir Med 2011;105(1):143-150.

17. Windisch W, Storre JH, Sorichter S, Virchow JC Jr. Comparison of volume- and pressure-limited NPPV at night: a prospective randomized cross-over trial. Respir Med 2005;99(1):52-59.

18. Krachman SL, Quaranta AJ, Berger TJ, Criner GJ. Effects of noninvasive positive pressure ventilation on gas exchange and sleep in COPD patients. Chest 1997;112(3):623-628.

19. Duiverman ML, Wempe JB, Bladder G, Vonk JM, Zijlstra JG, Kerstjens HA, Wijkstra PJ. Two-year home-based nocturnal noninvasive ventilation added to rehabilitation in chronic obstructive pulmonary disease patients: a randomized controlled trial. Respiratory Res 2011;12:112. doi:10.1186/1465-9921-12-112. 